\title{
Tourmaline Nanoparticles Doped Polyvinylidene Fluoride (PVDF) Nanofibers
}

\author{
Derman VATANSEVER BAYRAMOL *, Ahmet Ozgur AgIRGAN, Aylin YILDIZ \\ Tekirdag Namık Kemal University, Silahtaraga Mah., Universite 1. Sok., No:13, Corlu-Tekirdag, Turkey \\ crossref http://dx.doi.org/10.5755/j01.ms.26.3.22335
}

Received 20 December 2018; accepted 01 March 2019

\begin{abstract}
The aim of this work is to produce tourmaline (TM) doped polyvinylidene fluoride (PVDF) nano-composite fibers. TMcontaining PVDF nanofibers were produced via a horizontally located electrospinning unit. N,N-dimethylformamide (DMF) and acetone were used as solvents. The amount of PVDF or PVDF/TM in the polymer solution was 20 wt. $\%$. PVDF was dissolved in DMF in presence of heat by using a magnetic stirrer while TM powder was dispersed in Acetone in absence of heat by using an ultrasonic stirrer. These two solutions were then mixed for TM/PVDF nanocomposite fiber production. Pristine PVDF nanofibers were also electrospun as control samples. Produced nano-surfaces were analyzed under scanning electron microscopy (SEM), Fourier-transform Infrared Spectroscopy (FTIR), X-Ray Diffraction (XRD). Voltage generation capacities were investigated by recording the voltage outputs of samples under an applied rotational impact. The peak voltage produced by the TM doped PVDF nanocomposite fibers was higher than the PVDF nanofibers. Keywords: PVDF, tourmaline, electrospinning, SEM, FTIR, XRD, voltage output.
\end{abstract}

\section{INTRODUCTION}

Two topics encouraged researchers to work on renewable energy: one is that the World goes electronic and needs more electrical energy for devices and the other is the risk that energy raw materials may be consumed one day. Therefore, they have turned to renewable energy sources for the World's comprehensive energy need.

Piezoelectric materials are able to produce electrical charges as a result of applied mechanical stress, which allows them to be considered as a "smart material". The energy generated by a piezoelectric material can be called as renewable energy since it is activated by the mechanical stress, which will otherwise be wasted. It has been known since 1880s that some materials can show piezoelectric properties [1]. Early studies with polymer materials coincided with the end of the 1960s. PVDF is the first synthetic polymer to be recognized by its piezoelectric properties [2]. This polymer may contain crystalline phases such as alpha $(\alpha)$, beta $(\beta)$, gamma $(\gamma)$, delta $(\delta)$. One or more of these phases may be present at the same time in the polymer structure and one crystal phase can be transferred to another via mechanical, thermal, electrical fields [3]. Taking advantage of this feature, a significant number of studies have been carried out on producing piezoelectric PVDF films [4-11], fibers [12-16], nanofibers [17-21], fabrics [22-24] and so on.

Studies on PVDF based nanofiber and surface production have accelerated for last two decades and a number of research works have been carried out on nanoscale fiber production of PVDF with or without additives. Some of the additives doped into PVDF polymer solution are including but limited to PZT [25], graphene [26, 27], CNT [28], Ni [29], ZnO [30] and $\mathrm{Co}-\mathrm{ZnO}$ [31]. PVDF is not soluble in water and the solvents to dissolve this polymer are limited. Most of the works in the literature focus on Dimethylacetamide (DMAc or DMA), N,NDimethylmethylformamide (DMF), Tetrahydrofuran (THF), Methylethylketone (MEK) and their mixture with each other or Acetone [19, 32-35].

In this paper, the effect of dopping tourmaline nano particles in PVDF nanofibers was investigated. Surface morphology, fraction of $\beta$-phase and crystal structure of produced nanofibers were analyzed and evaluated by SEM, FTIR and XRD. Further, the voltage output of PVDF and PVDF/TM nanofibers were investigated under an impact applied by a motorized rotating arm.

\section{MATERIALS AND METHODS}

PVDF polymer and tourmaline powder were supplied by Solvay Solexis Ltd. and Shanghai HuZhengNano Technology Company, respectively. PVDF used in this study was a homopolymer with a melt flow index of $40 \mathrm{~g}$ per $10 \mathrm{~min}$ at $230{ }^{\circ} \mathrm{C}$ and $2.16 \mathrm{~kg}$ mass. Melting point and crystallization temperatures of the polymer was $\sim 175^{\circ} \mathrm{C}$ and $138^{\circ} \mathrm{C}$, respectively. The solvents; N,NDimethylformamide (DMF) and acetone were obtained from EMSURE® and TEKKIM, respectively.

Table 1. The content of polymer solutions used to electrospun nanofibers

\begin{tabular}{|c|c|c|c|c|}
\hline Sample ID & $\begin{array}{c}\text { PVDF, } \\
\text { wt.\% }\end{array}$ & $\begin{array}{c}\text { TM, } \\
\text { wt.\% }\end{array}$ & $\begin{array}{c}\text { DMF, } \\
\text { wt.\% }\end{array}$ & $\begin{array}{c}\text { Acetone, } \\
\text { wt.\% }\end{array}$ \\
\hline P20-0T & 20.00 & 0.00 & 56.00 & 24.00 \\
\hline P20-5T & 19.00 & 1.00 & 56.00 & 24.00 \\
\hline P20-10T & 18.00 & 2.00 & 56.00 & 24.00 \\
\hline P20-15T & 17.00 & 3.00 & 56.00 & 24.00 \\
\hline
\end{tabular}

Samples given in Table 1 contain $20 \mathrm{wt} \%$ by weight of polymer or TM doped polymer (PVDF/TM) in the polymer solution. The amount of TM doped in polymer was $0 \%$, $5 \%, 10 \%$ and $15 \%$ by weight. The letter $\mathrm{P}$ in the name of

\footnotetext{
* Corresponding author. Tel.: +90-282-2502392; fax: +90-282-2509924.

E-mail address: dvbayramol@nku.edu.tr (D. Vatansever Bayramol)
} 
the sample refers to the polymer, and the next number refers to the amount of polymer in the solution. The letter " $T$ " denotes tourmaline nanoparticles and the number in front of the letter indicates the weight percent of Tourmaline in the polymer. For instance, P20-5T sample is produced from $20 \%$ by weight of polymer/TM which contains 95 wt.\% PVDF and 5 wt.\% TM.

After several attempts of dissolving PVDF/TM in DMF/acetone (7:3), it was thought that the temperature should take the stage in order to allow the polymer to dissolve more rapidly in the solvent. For this reason, the polymer itself (PVDF) was first dissolved in DMF, which has a boiling temperature of $153{ }^{\circ} \mathrm{C}$ ) at $80^{\circ} \mathrm{C}$ via a magnetic stirrer while TM powder was introduced in acetone (with a boiling temperature of $55-56^{\circ} \mathrm{C}$ ) and stirred at room temperature. Once PVDF was dissolved completely in DMF, the polymer solution was let to cool down below $50{ }^{\circ} \mathrm{C}$. Two solution then mixed and stirring further at room temperature until homogeneous mixing of TM/acetone with PVDF/DMF was observed.

Nanofibers were produced via a Nanospinner-1 (Basic System) manufactured by Inovenso, Turkey. Due to the portable needle holder and the collector, Nanospinner-1 electrospinning unit allows nanofiber production in both horizontal and vertical ways. In this work, the needle and the collector were located horizontally. For the nanofiber production, it is necessary to optimize the variables such as the feed rate, the voltage to be applied and the distance between the needle and the collector. Therefore, different feed rates from $0.5 \mathrm{~mL} / \mathrm{h}$ to $7 \mathrm{~mL} / \mathrm{h}$ and voltages varying amounts between $0 \mathrm{kV}$ and $30 \mathrm{kV}$ applied to determine the appropriate conditions for production. The distance between the needle and the collector is fixed at $15 \mathrm{~cm}$. As a result of the trials and evaluations, the feed rate determined for the production of nanofiber surfaces to be produced within the scope of the project was determined as $1.5 \mathrm{~mL} / \mathrm{h}$. The applied voltage was determined as $13 \mathrm{kV}$ for the following productions. The nanofibers were collected on aluminum foil placed on the collector. The purpose of doing this is to prevent damage to the produced surfaces from the pickup. Surfaces, which are sure that the solvent is completely removed, have been subjected to the necessary analyzes with foil or stripping off the foil if necessary.

Images of the nanofibers produced were investigated by FEI brand QUANTA FEG 250 scanning electron microscope. Infrared spectroscopy of nano-porous surfaces was investigated by BRUKER brand VERTEX 70 ATR model Fourier transformed infrared spectrometer. Since the piezoelectric property in PVDF is related to the presence and amount of crystal structures in the material, the density changes in the peaks representing the $\beta$-crystal structure will inform us about the piezoelectricity of the material. The following formula will be used when making this evaluation $[23,30,35]$ :

$$
F(\beta)=\frac{A_{\beta}}{\left(\frac{K_{\beta}}{K_{\alpha}}\right) A_{\alpha}+A_{\beta}} .
$$

where $F(\beta)$ is the $\beta$-crystal structure in the material; $A$ is the absorbance at a given wavelength and $K$ is the absorption coefficient. The $\alpha$ and $\beta$ subscripts refer to the corresponding crystal structure. Absorption coefficients $K_{\alpha}$ and $K_{\beta}$ are $6.1 \times 104 \mathrm{~cm}^{2} /$ mole and $7.7 \times 104 \mathrm{~cm}^{2} /$ mole, respectively.

X-ray diffraction measurement of the produced nanofibers were performed by a PANalytical Empyrean brand XRD.

In order to evaluate the voltage outputs, produced nanofibers were placed between two aluminum layers acting as electrodes. The prepared samples were subjected to a mechanical effect by a $360^{\circ}$ swiveling arm and at adjustable speeds. As a result of the applied, the voltage generated by the sample was transferred to the oscilloscope through the aluminum layers that acted as electrodes. Voltage output values were monitored and recorded by a digital oscilloscope.

\section{RESULTS AND DISCUSSION}

Produced nanofibers were analyzed under scanning electron microscope to determine the fiber formation and surface morphologies.

SEM images given in Fig. 1 show that electrospun PVDF and PVDF/TM nanofibers were randomly oriented.
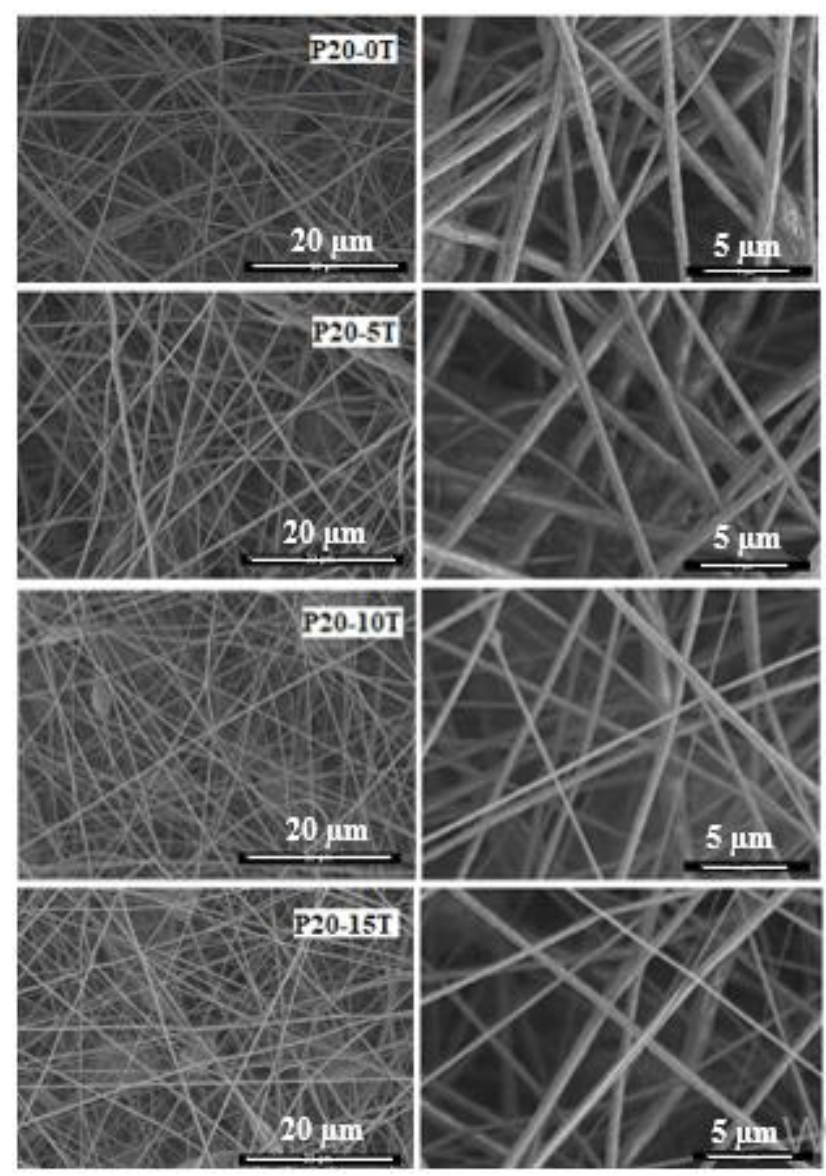

Fig. 1. SEM images of produced nanofibers. Images ordered in the left were taken with 5000 magnification (scale bar represents $20 \mu \mathrm{m}$ ) while the images captured and ordered in the right were taken with a magnification of 20000 (scale bar represents $5 \mu \mathrm{m}$ )

The surface morphology of P20-0TM has a rougher surface as compared to other three samples. Diameter distribution histograms of produced nanofibers are shown in Fig. 2. Average fiber diameters were found to be 
$271.5 \pm 171.2 \mathrm{~nm}$ for P20-0TM, $248.2 \pm 143.5 \mathrm{~nm}$ for P205TM, $175.7 \pm 112.7 \mathrm{~nm}$ for P20-10TM and $168 \pm 89.7 \mathrm{~nm}$ for P20-15TM. It is clear that the addition of TM in polymer resulted lower fiber diameter which is an agreement with a study carried out on PET/TM [36].
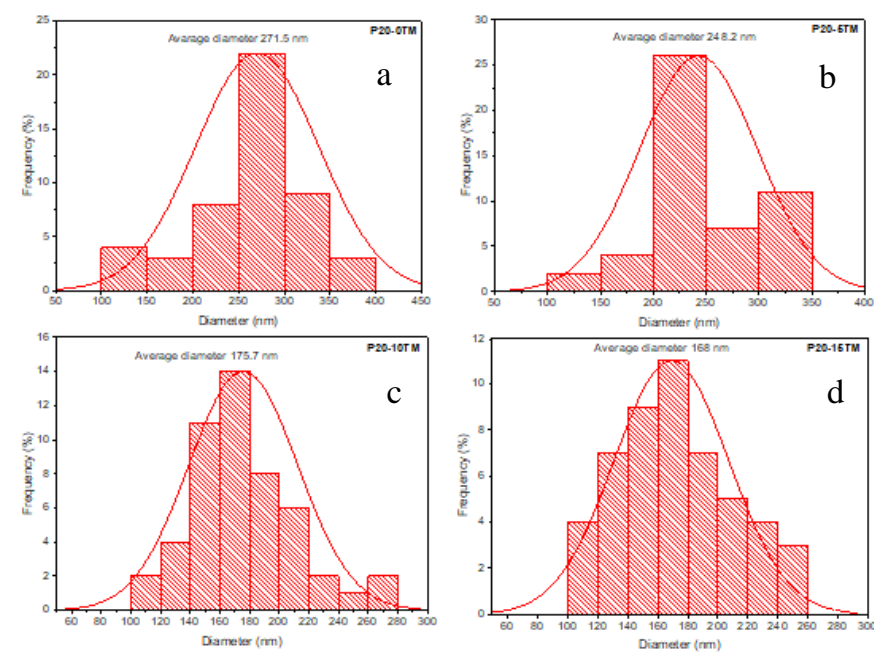

Fig. 2. Diameter distribution histograms: a-P20-0TM; b-P20-5TM; c-P20-10TM; d-P20-15TM composite nanofibers

In order to investigate the effect of TM nanoparticles on the formation of $\beta$-crystal structure, FTIR spectra of samples were investigated. The characteristic vibration bands of the produced samples were analyzed in the frequency range of $600-4000 \mathrm{~cm}^{-1}$. However, the vibration band range, which has high peak formation and which can provide us with sufficient information about the material, has been transferred to the graph. The finger print region spectra of nanofibers containing different amounts of TM nanoparticles are given in Fig. 3. The increase in the $\beta$ crystal structure here will indicate that the material shows more expressed piezoelectric properties.

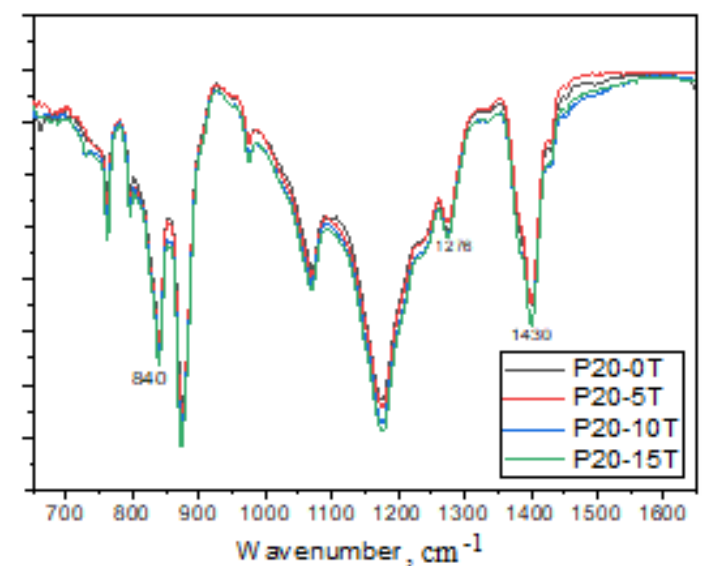

Fig. 3. FTIR analysis results of nanofibers containing $20 \mathrm{wt} . \%$ polymer/TM in solution. The amount of TM in polymer is 0 wt. $\%, 5$ wt. $\%, 10$ wt. $\%$ and 15 wt. $\%$

The peaks of $760 \mathrm{~cm}^{-1}, 796 \mathrm{~cm}^{-1}$ and $974 \mathrm{~cm}^{-1}$ which we see in the spectra refer to the $\alpha$-crystal structure of the material, and the excess of the $\alpha$-crystal structure in the material indicates that the material is non-polar. Therefore, the increase of the $\alpha$-crystal structure in the material is interpreted as the reduction of the piezoelectric property.

Piezoelectric properties of the material are related to $\beta$-, $\gamma$ - and $\delta$-crystal phases, which have polar character. The most important of these is the $\beta$-crystal phase and the presence of the material in the high $\beta$-crystal phase indicates that the PVDF material has good piezoelectric properties. The peaks in the spectra at the wavelengths of $840 \mathrm{~cm}^{-1}$, $1276 \mathrm{~cm}^{-1}$ and $1430 \mathrm{~cm}^{-1}$ are the $\beta$-crystal phase, whereas the other peaks are mostly related to $\gamma$-crystal phase. An increase in $\beta$-crystal structure has occurred with the increase in the amount of TM in the material, when Fig. 3 is examined together with the results obtained from Eq. 1.

$\mathrm{XRD}$ analysis was performed on the samples to support the FTIR results and to give more detailed information about the crystal structure of the material. To verify the presence of nanoparticles in produced nanocomposites and the formation of the beta-phase crystal structure, XRD analysis was performed on the samples and the results were processed with the Origin software.

When the graph shown in Fig. 4 is examined, the XRD peak, which is seen at an angle of $\sim 20.5^{\circ}$, shows the $\beta$ crystal phase formation in the nanocomposite structures we produced. XRD peaks at $\sim 18^{\circ}-19^{\circ}$ angles indicate $\alpha$ - and $\gamma$-crystal phase formation $[30,37]$. As can be seen, the addition of TM to the material resulted in an increase in both the $\alpha$-crystal structure of the material and the polar $\beta$ - and $\gamma$ crystal structures. However, with the increase of TM nanoparticles added to the material, the $\beta$-crystal phase increase which of prime importance to the piezoelectric property is clearly seen. Thus, it is possible to say that the XRD analysis results support the FTIR spectra and calculations.

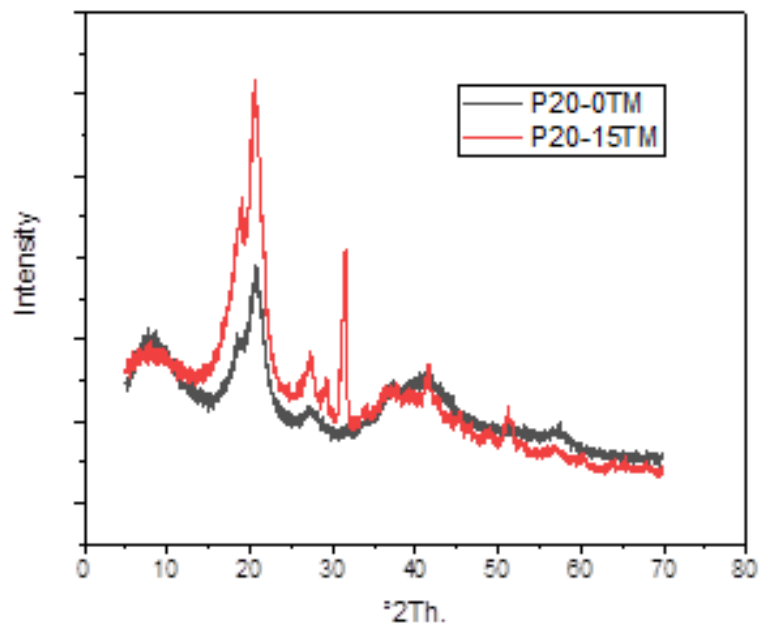

Fig. 4. X- ray diffractograms of PVDF (P20-0TM) and PVDF/TM (P20-15TM) nanofibers

As seen in Fig. 5 and Table 2, as the amount of TM in the material increased, detected voltage output was also increased. Because of the fact that a fixed collector is used and no drawing is applied, the most effective factors in the voltage production of produced materials are the TM nano crystals, and already existing $\beta$ - and $\gamma$-crystalline structures in PVDF. The peak voltage output of the nanofibers increased from $40 \mathrm{mV}$ to $72 \mathrm{mV}$ when $5 \mathrm{wt} . \%$ TM nanoparticles were added in polymer. When the amount of $\mathrm{TM}$ increased in the polymer increased further to $10 \mathrm{wt} . \%$ 
and $15 \mathrm{wt} . \%$, the detected peak voltage also increased further to $102 \mathrm{mV}$ and $136 \mathrm{mV}$, respectively.

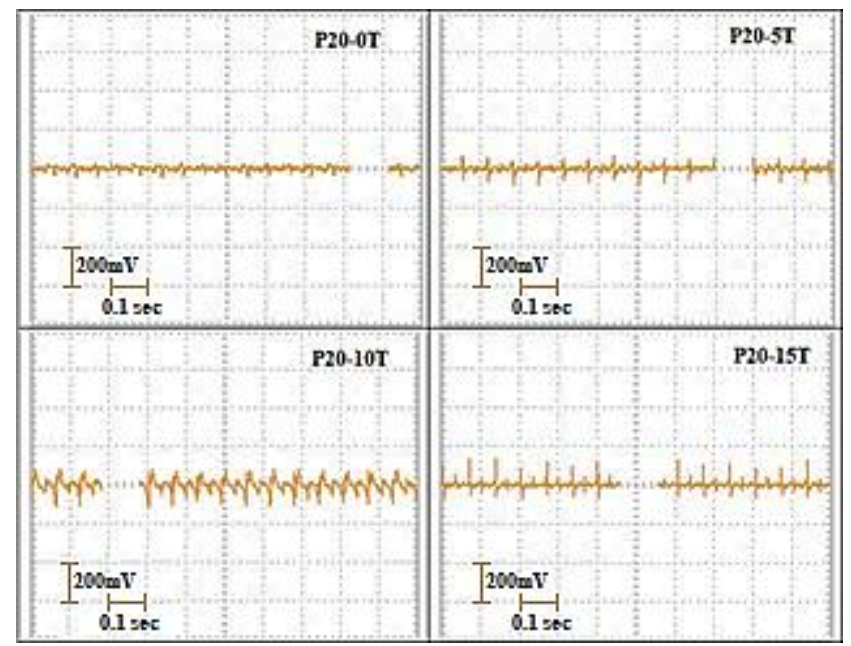

Fig. 5. Screenshots of the digital oscilloscope shows voltage outputs of samples under a mechanical impact applied by a motorized rotating arm. Per vertical division represents $200 \mathrm{mV}$, and per horizontal division represents $0.1 \mathrm{sec}$

Table 2. Voltage response of samples as a result of applied mechanical force

\begin{tabular}{|c|c|c|c|}
\hline Sample ID & $\begin{array}{c}\text { TM ratio in } \\
\text { polymer, } \\
\text { wt\% }\end{array}$ & $\begin{array}{c}\text { Peak voltage, } \\
\mathrm{mV}\end{array}$ & Increase, $\%$ \\
\hline P20-0T & 0 & 40 & - \\
\hline P20-5T & 5 & 72 & 90 \\
\hline P20-10T & 10 & 102 & 155 \\
\hline P20-15T & 15 & 136 & 240 \\
\hline
\end{tabular}

This is clearly shows the effect of TM nanoparticles on voltage output of the produced nanofibers. It is possible to say that all the results obtained, calculations and observations done in the work support each other.

\section{CONCLUSIONS}

The effect of TM nano particles on fiber formation, crystalline phase and voltage output of PVDF nanofibers was studied in this work. On SEM images, a decrease in fiber diameter was observed with an increase in TM ratio in polymer solution. Fraction of $\beta$-phase and crystalline structure of produced piezoelectric nanofibers were investigated by FTIR and XRD. The fraction of $\beta$-phase value increased with an increase in the amount of TM added in polymer solution. Analyzing XRD patterns, a more intensive peak at $2 \theta=20.5^{\circ}$ was observed on P20-15TM when compared to P20-0TM. The voltage output up to $240 \%$ was recorded when the amount of the TM was increased up to $15 \mathrm{wt} . \%$ in polymer. Therefore, it is possible to conclude that addition of TM in PVDF yield thinner fiber diameter, higher $\beta$-phase content and voltage output. However, voltage generation capacity is expected to further increase if a rotating collector is used. Therefore, it is planned to examine the characteristics of samples produced at different rotational speeds by adding a speed-adjustable rotary collector to the device as a further study.

\section{Acknowledgments}

This work was supported by Scientific Research Projects Coordination Unit of Tekirdag Namik Kemal University. "Project number NKUBAP.06.GA.17.093"

\section{REFERENCES}

1. Curie, J., Curie, P. "Développement Par Compression de L'électricité Polaire Dans les Cristaux Hémièdres à Faces Inclines Bulletin de la Societe de Minerologique de Franceompt Rend 3 1880: pp. 90-93. https://doi.org/10.3406/bulmi.1880.1564

2. Kawai, H. The Piezoelectricity of Poly (vinylidene fluoride) Japanese Journal of Applied Physics 8(7) 1969: pp. $975-975$. https://doi.org/10.1143/JJAP.8.975

3. Gallantree, H.R. Review of Transducer Applications of Polyvinylidene Fluoride IEEE Proceedings 130 (5) 1983: pp. 219-224.

http://dx.doi.org/10.1049/ip-i-1.1983.0040

4. Ambrosy, A., Holdik, K. Piezoelectric PVDF Films as Ultrasonic Transducers Journal of Physics E: Scientific Instruments 17 1984: pp. 856-859. https://doi.org/10.1088/0022-3735/17/10/011

5. Hausler, E., Stein, L., Harbauer, G. Implantable Physiological Power Supply with PVDF Film Ferroelectrics 60 1984: pp. $277-282$. https://doi.org/10.1080/00150198408017528

6. Kaura, T., Nath, R., Perlman, M.M. Simultaneous Stretching and Corona Poling of PVDF Films Journal of Physics D: Applied Physics 24 (10) 1991: pp. $1848-1852$. https://doi.org/10.1088/0022-3727/24/10/020

7. Kumar, A., Periman, M.M. Simultaneous Stretching and Corona Poling of PVDF and P(VDF-TriFE) Films II Journal of Physics D: Applied Physics 26 (3) 1993: pp. 469-473. https://doi.org/10.1088/0022-3727/26/3/020

8. Salimi, A., Yousefi, A.A. Analysis Method: FTIR Studies of $\beta$-phase Crystal Formation in Stretched PVDF Films Polymer Testing 22 (6) 2003: pp. 699-704. https://doi.org/10.1016/S0142-9418(03)00003-5

9. Mahato, P.K., Seal, A., Garain, S., Sen, S. Effect of Fabrication Technique on the Crystalline Phase Materials Science-Poland 33 (1) 2015: pp. 157-162. https://doi.org/10.1515/msp-2015-0020

10. Li, S., Crovetto, A., Peng, Z., Zhang, A., Hansen, O., Wang, M., Li, X., Wang, F. Bi-resonant Structure with Piezoelectric PVDF Films for Energy Harvesting from Random Vibration Sources at Low Frequency Sensors and Actuators A: Physical 247 2016: pp. 547-554. https://doi.org/10.1016/j.sna.2016.06.033

11. Hoque, N.A, Thakur, P., Roy, S., Kool, A., Bagchi, B., Biswas, P., Saikh, M.M., Khatun, F., Das, S., Ray, P.P. Er3+/Fe3+ Stimulated Electroactive, Visible Light Emitting, and High Dielectric Flexible PVDF Film Based Piezoelectric Nanogenerators: A Simple and Superior SelfPowered Energy Harvester with Remarkable Power Density ACS Applied Materials \& Interfaces 9(27) 2017: pp. $23048-23059$. https://pubs.acs.org/doi/10.1021/acsami.7b08008

12. Ferreira, A., Costa, P., Carvalho, H., Nobrega, J. Extrusion of Poly(vinylidene fluoride) Filaments: Effect of the Processing Conditions and Conductive Inner Core on the 
Electroactive Phase Content and Mechanical Properties Journal of Polymer Research 18 (6) 2011: pp. 1653-1658. https://doi.org/10.1007/s10965-011-9570-1

13. Hadimani, R.L., Bayramol, D.V., Sion, N., Shah, T., Qian, L., Shi, S., Siores, E. Continuous Production of Piezoelectric PVDF Fibre for E-Textile Applications Smart Materials and Structures 22(7) 2013: pp. 075017-1 - 075017-7.

https://doi.org/10.1088/0964-1726/22/7/075017

14. Lund, A. Melt Spun Piezoelectric Textile Fibres - An Experimental Study. PhD Thesis, Chalmers University of Technology, Sweden, 2013.

15. Guo, Z., Nilsson, E., Rigdahl, M., Hagstrom, B. Melt Spinning of PVDF Fibers with Enhanced $\beta$-Phase Structure Journal of Applied Polymer Science $130(4)$ 2013: pp. 2603-2609. https://doi.org/10.1002/app.39484

16. Bayramol, D.V. Effects of Tourmaline on the Voltage Response of PVDF Filaments Industria Textila 68 (1) 2017: pp. $47-53$.

17. Tamberg, K.G. Effect of Electrospinning Conditions on Morphology of PVDF Fibers Thesis at Tallinn University of Technology Faculty of Chemical and Materials Technology Department of Polymer Materials, Estonia, 2014.

18. Mokhtari, F., Latifi, M., Shamshirsaz, M. Electrospinning/electrospray of Polyvinylidene Fluoride (PVDF): Piezoelectric Nanofibers The Journal of the Textile Institute 107 2015: pp. $1037-1055$. https://doi.org/10.1080/00405000.2015.1083300

19. Mokhtari, F., Shamshirsaz, M., Latifi, M., Asadi, S. Comparative Evaluation of Piezoelectric Response of Electrospun PVDF (Polyvinilydine fluoride) Nanofiber with Various Additives for Energy Scavenging Application The Journal of the Textile Institute 108 (6) 2017: pp. 906-914. https://doi.org/10.1080/00405000.2016.1202091

20. Asai, H., Kikuchi, M., Shimada, N., Nakane, K. Effect of Melt and Solution Electrospinning on the Formation and Structure of Poly(vinylidene fluoride) Fibres RSC Advances 7(29) 2017: pp. 17593-17598. https://doi.org/10.1039/C7RA01299C

21. Motamedi, A.S., Mirzadeh, H., Hajiesmaeilbaigi, F., Bagheri-Khoulenjani, S., Shokrgozar, M.A. Effect of Electrospinning Parameters on Morphological Properties of PVDF Nanofibrous Scaffolds Progress in Biomaterials 6 2017: pp. $113-123$.

https://doi.org/10.1007/s40204-017-0071-0

22. Wang, Y.R., Zheng, J.M., Ren, G.Y., Zhang, P.H., Xu, C. A Flexible Piezoelectric Force Sensor Based on PVDF Fabrics Smart Materials and Structures $20(4)$ 2011: pp. 045009-1 - 045009-6. https://doi.org/10.1088/0964-1726/20/4/045009

23. Soin, N., Shah, T.H., Anand, S.C., Geng, J., Pornwannachai, W., Mandal, P., Reid, D., Sharma, S., Hadimani, R.L., Bayramol, D.V., Siores, E. Novel "3-D Spacer" All Fibre Piezoelectric Textiles for Energy Harvesting Applications Energy \& Environmental Science 7 (5) 2014: pp. 1670-1679.

https://doi.org/10.1039/C3EE43987A

24. Tajitsu, Y. Smart Piezoelectric Fabric and Its Application to Control of Humanoid Robot Ferroelectrics 499 2016: pp. 36-46. https://doi.org/10.1080/00150193.2016.1171982

25. Yun, J.S., Park, C.K., Jeong, Y.H., Cho, J.H., Paik, J.H., Yoon, S.H., Hwang, K.R. The Fabrication and
Characterization of Piezoelectric PZT/PVDF Electrospun Nanofiber Composites Nanomaterials and Nanotechnology 6 (20) 2016: pp. 62433-1-62433-5.

https://doi.org/10.5772/62433

26. Bera, B., Mandal, D., Sarkar, M.D. Sensor Made of $\mathrm{PVDF} /$ graphene Electrospinning Fiber and Comparison between Electrospinning PVDF Fiber and PVDF/graphene Fiber Imperial Journal of Interdisciplinary Research 2 (5) 2016: pp. $1411-1413$.

27. Elashmawi, I.S., Alatawi, N.S., Elsayed, N.H. Preparation and Characterization of Polymer Nanocomposites Based on PVDF/PVC Doped with Graphene Nanoparticles Results in Physics 7 2017: pp. 636-640. https://doi.org/10.1016/j.rinp.2017.01.022

28. Wang, S.H., Wan, Y., Sun, B., Liu, L.Z., Xu, W. Mechanical and Electrical Properties of Electrospun PVDF/MWCNT Ultrafine Fibers Using Rotating Collector Nanoscale Research Letters 9(1) 2014: pp. 522-1 - 522-7. https://doi.org/10.1186/1556-276X-9-522

29. Sheikh, F.A., Cantu, T., Macossay, J., Kim, H. Fabrication of Poly(vinylidene fluoride) (PVDF) Nanofibers Containing Nickel Nanoparticles as Future Energy Server Materials Science of Advanced Materials 3 (2) 2011: pp. 216-222. https://doi.org/10.1166/sam.2011.1148

30. Bafqi, M.S.S., Bagherzadeh, R., Latifi, M. Fabrication of Composite PVDF-ZnO Nanofiber Mats by Electrospinning for Energy Scavenging Application with Enhanced Efficiency Journal of Polymer Research 22 2015: pp. 130-1 - 130-9. https://doi.org/10.1007/s10965-015-0765-8

31. Parangusan, H., Ponnamma, D., Al-Maadeed, M.A.A. Stretchable Electrospun PVDFHFP/Co-ZnO Nanofibers as Piezoelectric Nanogenerators Scientific Reports 8 2018: pp. 754-1 - 754-11. https://doi.org/10.1038/s41598-017-19082-3

32. Koombhongse, S., Liu, W.X., Reneker, D.H. Flat Polymer Ribbons and Other Shapes by Electrospinning Journal of Polymer Science Part B: Polymer Physics $\quad 39$ 2001: pp. 2598-2606. https://doi.org/10.1002/polb.10015

33. Park, Y.J., Kang, Y.S., Park, C. Micropatterning of Semicrystalline Poly(vinylidene fluoride) (PVDF) Solutions European Polymer Journal 41 (5) 2005: pp. 1002 - 1012. https://doi.org/10.1016/j.eurpolymj.2004.11.022

34. Zhao, X., Cheng, J., Chen, S., Zhang, J., Wang, X. Controlled Crystallization of Poly(vinylidene fluoride) Chains from Mixed Solvents Composed of Its Good Solvent and Nanosolvent Journal of Polymer Science Part B: Polymer Physics 48 2010: pp. 575-581. https://doi.org/10.1002/polb.21924

35. Mahale, B., Bodas, D., Gangal, S.A. Study of $\beta$-phase Development in Spin-coated PVDF Tthick Films Bulletin of Materials Science 4 (3) 2017: pp. 569-575. https://doi.org/10.1007/s12034-017-1390-4

36. Safak, S., Karaca, E. Production and Characterization of Poly(ethylene terephthalate) Nanofibrous Mat Including Tourmaline Additive Textile Research Journal 86 (15) 2016: pp. $1651-1658$. https://doi.org/10.1177/0040517515617418

37. Abdullah, I.Y., Yahaya, M., Jumali, M.H.H., Shanshool, H.M. Influence of Temperature on Crystalline Structure of Polyvinylidene Fluoride International Journal of Technical Research and Applications 23 2015: pp. 46-50. 